8 Wambach JA, Wegner DJ, Depass K, et al. Single ABCA3 mutations increase risk for neonatal respiratory distress syndrome. Pediatrics, 130: e1575-e1582.

9 Bullard JE, Nogee LM. Heterozygosity for ABCA3 mutations modifies the severity of lung disease associated with a surfactant protein C gene (SFTPC) mutation. Pediatr Res 2007; 62: 176-179.

10 Thouvenin G, Nathan N, Epaud R, et al. Diffuse parenchymal lung disease caused by surfactant deficiency: dramatic improvement by azithromycin. BMJ Case Rep 2013 [in press DOI: 10.1136/bcr-2013-009988].

\title{
Pulmonary arterial hypertension in familial hemiplegic migraine with ATP1A2 channelopathy
}

\begin{abstract}
To the Editor:
Pulmonary arterial hypertension (PAH) has been the focus of major research in recent years [1]. Involvement of mutations in genes encoding for members of the transforming growth factor- $\beta$ signalling pathway (BMPR2, ACVRL1, ENG and SMAD8) has been demonstrated in the development of heritable $\mathrm{PAH}$, allowing novel experimental and clinical approaches [2-4]. However, $\sim 30 \%$ of familial forms of PAH remain without any identification of genetic mutations. Recently, mutations of the KCNK3 gene (encoding $\mathrm{K}^{+}$channel subfamily $\mathrm{K}$ member 3 ) have been reported in patients with familial and sporadic PAH [5]. KCNK3 belongs to a family of mammalian $\mathrm{K}^{+}$channels, and are involved in the regulation of resting membrane potential, pulmonary vascular tone and in vascular remodelling. This result paves the way to the involvement of novel signalling pathways in the development of heritable PAH. Herein, we describe a novel association of PAH and a channelopathy due to mutation in ATP1A2 (encoding the $\alpha 2$-subunit of the $\mathrm{Na}^{+} / \mathrm{K}^{+}$-ATPase), a mutation known to cause familial hemiplegic migraine (FHM), a rare autosomal dominant disease [6].
\end{abstract}

A 24-year-old male was referred with a 1-year history of progressive exertional dyspnoea. Since the age of 8 years, he has reported recurrent episodes of hemiplegic migraine associated with muscle weakness and pain. The proband's mother (II4) (fig. 1) and two of his brothers (III6 and III7) had recurrent hemiplegic migraine with aura. There was no familial history of PAH. On admission, the patient was in New York Heart Association (NYHA) functional class III. His 6-min walk distance (6MWD) was 409 m. Pulmonary function tests were normal except for decreased diffusing capacity of the lungs for carbon monoxide. Doppler transthoracic echocardiography revealed signs of severe pulmonary hypertension with an estimated systolic pulmonary artery pressure of $75 \mathrm{mmHg}$, right ventricular dilatation and hypertrophy, and mild pericardial effusion. Right heart catheterisation confirmed pre-capillary pulmonary hypertension, with a mean pulmonary artery pressure $(\mathrm{mPAP})$ of $51 \mathrm{mmHg}$, a pulmonary capillary wedge pressure of $12 \mathrm{mmHg}$, a right atrial pressure of $7 \mathrm{mmHg}$, a cardiac index of $1.90 \mathrm{~L} \cdot \mathrm{min}^{-1} \cdot \mathrm{m}^{-2}$ and pulmonary vascular resistance (PVR) of 12.3 Wood units. No acute vasodilator response to nitric oxide was observed. Screening for other causes of pulmonary hypertension was negative. The patient was treated with a combination of intravenous epoprostenol, an endothelin receptor antagonist (ERA) and a phosphodiesterase type 5 inhibitor (PDE5i). The patient stopped taking the PDE5i after a few days because of side-effects, including increased symptoms of migraine. 4 months later, re-evaluation showed moderate clinical (NYHA functional class II and 6MWD $518 \mathrm{~m}$ ) and haemodynamic improvement (mPAP $43 \mathrm{mmHg}$, cardiac index $2.29 \mathrm{~L} \cdot \mathrm{min}^{-1} \cdot \mathrm{m}^{-2}$ and PVR 8.4 Wood units). The patient is still alive 1 year after diagnosis on intravenous epoprostenol and an ERA.

According to our local procedures, the patient underwent genetic counselling and gave written informed consent for genetic screening. No point mutations or large rearrangements of the BMPR2 and ACVRL1 genes were identified. To date, three genes (CACNA1A, ATP1A2 and SCNA1) encoding ion transporters are known to be associated with FHM. Genetic analysis revealed a nucleotide substitution in the coding sequence of the ATP1A2 gene (c.2819C>T; p.S940L) located on chromosome 1 (1q23). This mutation, which was not found in 200 control chromosomes, and was absent from the dbSNP, 1000 Genomes and Exome Sequencing Project data, affects a highly conserved amino acid, but has never been reported before. The patient's brothers, III4 and III6, were screened for the familial ATP1A2 mutation. Patient III4 did not carry the familial mutation and, as suggested by the clinical symptoms, the mutation was identified in patient III6 (fig. 1). Mutations of the ATP1A2 gene are known to cause FHM, a rare autosomal dominant disease characterised by migraine with motor weakness and aura [6]. Other neurological symptoms include 


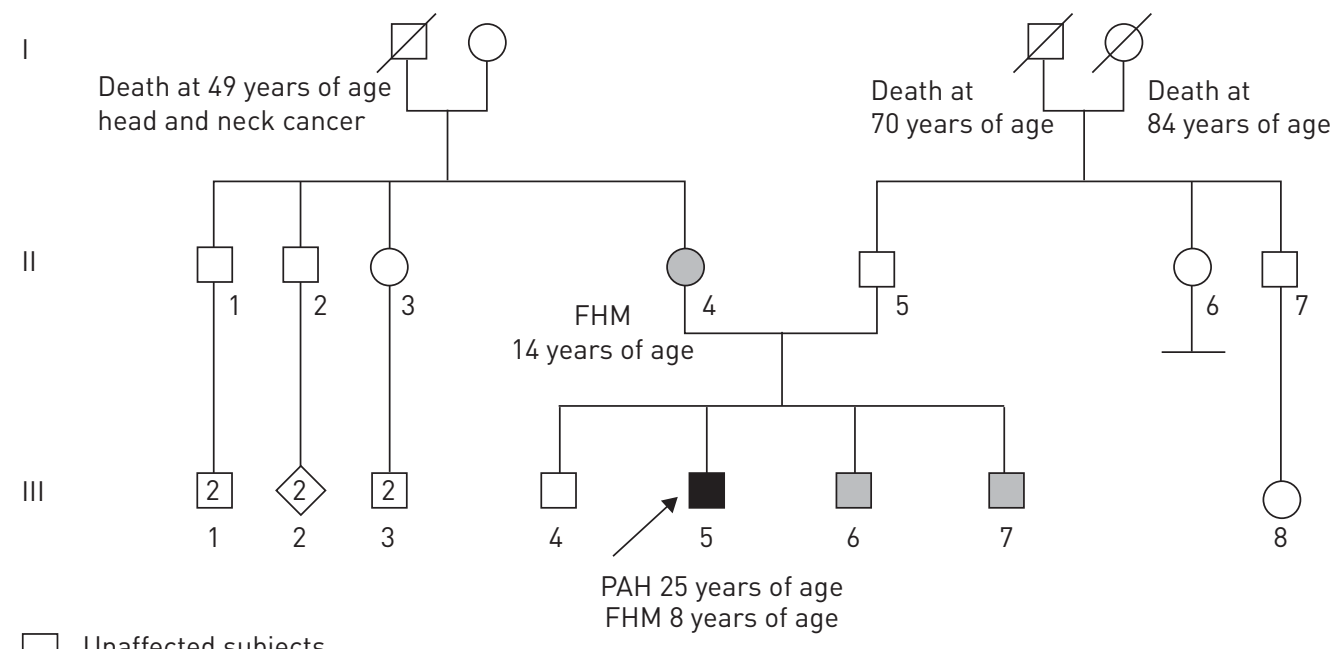

Unaffected subjects

$\mathrm{PAH}+\mathrm{FHM}$

FHM

FIGURE 1 Family tree. Ages indicated are those at pulmonary arterial hypertension (PAH) diagnosis or the beginning of familial hemiplegic migraine (FHM) symptoms. Arrow: proband.

various types of epileptic seizures and intellectual deficit; permanent cerebellar signs may be present in patients carrying a CACNA1A mutation [6]. FHM has an estimated prevalence of one in 20000, 20-30\% of cases carrying an ATP1A2 mutation [6]. In France, only 216 FHM patients (126 families) carry an ATP1A2 mutation (unpublished data).

The association of two rare diseases (PAH and FHM) supports the hypothesis of a potential common pathophysiological link. It is important to note that the presence and the activity of the $\alpha 2$-subunit of the $\mathrm{Na}^{+} / \mathrm{K}^{+}$-ATPase in lung and, more particularly, in pulmonary vascular smooth muscle cells have been previously reported [7]. In addition, several studies have reported substantial decreases in expression and/or activity of different types of $\mathrm{K}^{+}$channels in pulmonary arterial smooth muscle cells of patients displaying idiopathic $\mathrm{PAH}$, together with abnormalities in resting membrane potential and $\mathrm{Ca}^{2+}$ homeostasis [8]. Furthermore, pulmonary hypertension improvement has been demonstrated by restoring the expression of $\mathrm{K}^{+}$channels in a chronic hypoxic pulmonary hypertension rodent model (by treatment with a voltage-gated $\mathrm{K}^{+}(\mathrm{KV})$ channel activator or by gene transfer using adenovirus carrying the human Kv1.5 gene (KCNA5)) $[9,10]$. The chemical gradient produced by the normal activity of the $\mathrm{Na}^{+} / \mathrm{K}^{+}$-ATPase is important for restoration of low intracellular $\mathrm{Ca}^{2+}$ concentration. Inhibition of $\mathrm{K}^{+}$channels leads to an increase in intracellular $\mathrm{Ca}^{2+}$ concentration, which is a major stimulus for cell growth, migration and vasoconstriction [11]. Notably, inhibition of the $\mathrm{Na}^{+} / \mathrm{K}^{+}$-ATPase by ouabain rapidly activates the Ras/mitogen-activated protein kinase (MAPK) signalling pathway, leading to the proliferation of cultured vascular smooth cells [12, 13]. Interestingly, we have reported eight cases of neurofibromatosis type 1 and one case of Cowden syndrome associated with pre-capillary pulmonary hypertension [14]. Neurofibromatosis type 1 and Cowden syndrome are due to mutations in the NF1 and PTEN genes, respectively, leading to the activation of the Ras/MAPK signalling pathway and proliferation. Finally, it has been demonstrated that a decreased activity of $\mathrm{K}^{+}$channels can inhibit apoptosis by attenuating the activity of intracellular caspases [11]. Altogether, these observations support a possible role of mutations in ATP1A2 gene in the development of PAH through the disturbance of intracellular $\mathrm{Ca}^{2+}$ and $\mathrm{K}^{+}$concentrations.

We thus suggest that mutations in the ATP1A2 gene may contribute to pulmonary arterial remodelling and $\mathrm{PAH}$. However, we must emphasise that our report of a single family remains hypothesis-generating and requires future additional information. Importantly, no other families with mutations in ATP1A2 with a history of PAH have been reported to date. In addition, within the present family, the phenotype of FHM segregates with the ATP1A2 mutation, but only one member has PAH. While this family is intriguing, it remains possible that $\mathrm{PAH}$ is unrelated to the ATP1A2 mutation or FHM. Although these are both rare diseases, there is a small number of patients who do have coincidental rare diseases. In the future, our task will be to demonstrate the presence of ATP1A2 mutations in other individuals with PAH and/or functionally demonstrate how the mutation may affect the pulmonary vasculature. Similarly, patients displaying hereditary haemorrhagic telangiectasia and PAH have been very rarely reported in the past. 
Currently, $<50$ heritable PAH cases have been reported in ACVRL1 mutation carriers, while most mutation carriers develop hereditary haemorrhagic telangiectasia by the age of 60 years, emphasising that a single gene may cause different vascular diseases, alone or in combination, with markedly different penetrance [15]. In conclusion, our present case report reinforces the potential interest of ion channels in the pathogenesis of PAH.

@ERSpublications

This case report reinforces the potential interest of ion channels in the pathogenesis of PAH http://ow.ly/qkDD1

David Montani ${ }^{1,2,3}$, Barbara Girerd ${ }^{1,2,3}$, Sven Günther ${ }^{1,2,3}$, Florence Riant ${ }^{4,5}$, Elisabeth Tournier-Lasserve ${ }^{4,5}$, Laurent Magy ${ }^{6}$, Nizar Maazi ${ }^{7}$, Christophe Guignabert ${ }^{1,2,3}$, Laurent Savale ${ }^{1,2,3}$, Olivier Sitbon ${ }^{1,2,3}$, Gérald Simonneau ${ }^{1,2,3}$, Florent Soubrier ${ }^{8,9,10}$ and Marc Humbert ${ }^{1,2,3}$

${ }^{1}$ Université Paris-Sud, Le Kremlin-Bicêtre, ${ }^{2}$ Assistance Publique-Hôpitaux de Paris (AP-HP), Service de Pneumologie, DHU Thorax Innovation (DHU TORINO), Hôpital Bicêtre, Le Kremlin-Bicêtre, ${ }^{3}$ Institut National de la Santé et de la Recherche Médicale (INSERM) Unité Mixte de Recherche en Santé (UMR_S) 999, LabEx LERMIT, Centre Chirurgical Marie Lannelongue, Le Plessis Robinson, ${ }^{4}$ Service de Génétique Neuro-Vasculaire, AP-HP, Centre de Référence des Maladies Vasculaires Rares du Cerveau et de L'œil, Groupe Hospitalier Lariboisière - Fernand Widal, Paris, ${ }^{5}$ INSERM UMR_S 740, Université Paris Diderot, Sorbonne Paris Cité, Paris, ${ }^{6}$ Service de Neurologie, CHU de Limoges, Hôpital Dupuytren, Limoges, ${ }^{7}$ Service de Cardiologie, CHU de Limoges, Hôpital Dupuytren, Limoges, ${ }^{8}$ UMR_S 956, Université Pierre \& Marie Curie (UPMC), Université Paris 06, INSERM, Paris, ${ }^{9}$ Genetics Dept, Hôpital Pitié-Salpêtrière, AP-HP, Paris, and ${ }^{10}$ Institute for Cardiometabolism and Nutrition (ICAN), Paris, France.

Correspondence: D. Montani, Service de Pneumologie, Centre de Référence de l'Hypertension Pulmonaire Sévère, Hôpital de Bicêtre, AP-HP, 78 rue du Général Leclerc, 94275 Le Kremlin Bicêtre, France. E-mail: david.montani@ bct.aphp.fr

Received: Aug 222013 | Accepted after revision: Sept 242013 | First published online: Oct 172013

Conflict of interest: Disclosures can be found alongside the online version of this article at www.erj.ersjournals.com

Acknowledgements: The authors thank M. Eyries (Laboratoire d'Oncogénétique et Angiogénétique Moléculaire, Groupe Hospitalier Pitié-Salpétrière, Paris, France) for the genetic analysis of BMPR2 and ACVRL1.

\section{References}

1 Voelkel NF, Gomez-Arroyo J, Abbate A, et al. Pathobiology of pulmonary arterial hypertension and right ventricular failure. Eur Respir J 2012; 40: 1555-1565.

2 Liu D, Liu QQ, Eyries M, et al. Molecular genetics and clinical features of Chinese idiopathic and heritable pulmonary arterial hypertension patients. Eur Respir J 2012; 39: 597-603.

3 Frydman N, Steffann J, Girerd B, et al. Pre-implantation genetic diagnosis in pulmonary arterial hypertension due to BMPR2 mutation. Eur Respir J 2012; 39: 1534-1535.

4 Reynolds AM, Holmes MD, Danilov SM, et al. Targeted gene delivery of BMPR2 attenuates pulmonary hypertension. Eur Respir J 2012; 39: 329-343.

5 Ma L, Roman-Campos D, Austin ED, et al. A novel channelopathy in pulmonary arterial hypertension. $N$ Engl J Med 2013; 369: 351-361.

6 Russell MB, Ducros A. Sporadic and familial hemiplegic migraine: pathophysiological mechanisms, clinical characteristics, diagnosis, and management. Lancet Neurol 2011; 10: 457-470.

7 Ghosh B, Kar P, Mandal A, et al. $\mathrm{Ca}^{2+}$ influx mechanisms in caveolae vesicles of pulmonary smooth muscle plasma membrane under inhibition of $\alpha 2 \beta 1$ isozyme of $\mathrm{Na}^{+} / \mathrm{K}^{+}$-ATPase by ouabain. Life Sci 2009; 84: 139-148.

8 Yuan JX, Aldinger AM, Juhaszova M, et al. Dysfunctional voltage-gated $\mathrm{K}^{+}$channels in pulmonary artery smooth muscle cells of patients with primary pulmonary hypertension. Circulation 1998; 98: 1400-1406.

9 Morecroft I, Murray A, Nilsen M, et al. Treatment with the Kv7 potassium channel activator flupirtine is beneficial in two independent mouse models of pulmonary hypertension. Br J Pharmacol 2009; 157: 1241-1249.

10 Pozeg ZI, Michelakis ED, McMurtry MS, et al. In vivo gene transfer of the $\mathrm{O}_{2}$-sensitive potassium channel $\mathrm{Kv}_{\mathrm{v}} 1.5$ reduces pulmonary hypertension and restores hypoxic pulmonary vasoconstriction in chronically hypoxic rats. Circulation 2003; 107: 2037-2044.

11 Kuhr FK, Smith KA, Song MY, et al. New mechanisms of pulmonary arterial hypertension: role of $\mathrm{Ca}^{2+}$ signaling. Am J Physiol Heart Circ Physiol 2012; 302: H1546-H1562.

12 Aydemir-Koksoy A, Abramowitz J, Allen JC. Ouabain-induced signaling and vascular smooth muscle cell proliferation. J Biol Chem 2001; 276: 46605-46611.

13 Kometiani P, Li J, Gnudi L, et al. Multiple signal transduction pathways link $\mathrm{Na}^{+} / \mathrm{K}^{+}$-ATPase to growth-related genes in cardiac myocytes. The roles of Ras and mitogen-activated protein kinases. J Biol Chem 1998; 273: 15249-15256.

14 Montani D, Coulet F, Girerd B, et al. Pulmonary hypertension in patients with neurofibromatosis type I. Medicine (Baltimore) 2011; 90: 201-211.

15 Girerd B, Montani D, Coulet F, et al. Clinical outcomes of pulmonary arterial hypertension in patients carrying an ACVRL1 (ALK1) mutation. Am J Respir Crit Care Med 2010; 181: 851-861. 